Review

\title{
Prevalence and Associated Factors of Frailty and Mortality in Patients with End-Stage Renal Disease Undergoing Hemodialysis: A Systematic Review and Meta-Analysis
}

\author{
Hyeon-Ju Lee ${ }^{1(\mathbb{D})}$ and Youn-Jung Son ${ }^{2, *(\mathbb{D})}$ \\ 1 Department of Nursing, Tongmyong University, Busan 48520, Korea; lhj209@tu.ac.kr \\ 2 Red Cross College of Nursing, Chung-Ang University, Seoul 06974, Korea \\ * Correspondence: yjson@cau.ac.kr; Tel.: +82-2-820-5198
}

check for updates

Citation: Lee, H.-J.; Son, Y.-J.

Prevalence and Associated Factors of Frailty and Mortality in Patients with End-Stage Renal Disease Undergoing Hemodialysis: A Systematic Review and Meta-Analysis. Int. J. Environ.

Res. Public Health 2021, 18, 3471

https://doi.org/10.3390/

ijerph18073471

Received: 2 February 2021

Accepted: 24 March 2021

Published: 27 March 2021

Publisher's Note: MDPI stays neutral with regard to jurisdictional claims in published maps and institutional affiliations.

Copyright: (c) 2021 by the authors. Licensee MDPI, Basel, Switzerland This article is an open access article distributed under the terms and conditions of the Creative Commons Attribution (CC BY) license (https:// creativecommons.org/licenses/by/ $4.0 /)$.

\begin{abstract}
Hemodialysis is the most common type of treatment for end-stage renal disease (ESRD) Frailty is associated with poor outcomes such as higher mortality. ESRD patients have a higher prevalence of frailty. This systematic review and meta-analysis aimed to identify the prevalence and associated factors of frailty and examine whether it is a predictor of mortality among ESRD patients undergoing hemodialysis. Five electronic databases including PubMed, Embase, CINAHL, Web of Science, and Cochrane Library were searched for relevant studies up to 30 November 2020. A total of 752 articles were found, and seven studies with 2604 participants in total were included in the final analysis. The pooled prevalence of frailty in patients with ESRD undergoing hemodialysis was $46 \%$ (95\% Confidence interval (CI) 34.2-58.3\%). Advanced age, female sex, and the presence of diabetes mellitus increased the risk of frailty in ESRD patients undergoing hemodialysis. Our main finding showed that patients with frailty had a greater risk of all-cause mortality compared with those without (hazard ratio (HR): $2.02,95 \%$ CI: 1.65-2.48). To improve ESRD patient outcomes, healthcare professionals need to assess the frailty of older ESRD patients, particularly by considering gender and comorbidities. Comprehensive frailty screening tools for ESRD patients on hemodialysis need to be developed.
\end{abstract}

Keywords: frailty; kidney disease; hemodialysis; mortality; risk factor; systematic review

\section{Introduction}

Chronic kidney disease (CKD) is a progressive loss in kidney function and an irreversible clinical syndrome that is characterized by the kidney's failure to filter waste products and remove excessive fluid from the body [1]. The global prevalence of CKD has been reported to be 8-16\% [2]. End-stage renal disease (ESRD) represents a serious public health problem fueled by aging populations and a pandemic of chronic noncommunicable diseases [3,4]. Although overall mortality rate of the ESRD population is improving, the mortality rate has been reported to be up to $30 \%$ within the first year of transition from CKD to ESRD [5,6]. In particular, rapid progression of CKD is associated with worse clinical outcomes, such as cardiovascular events and death [6].

To maintain daily life activities, renal replacement therapy is commonly used for ESRD in clinical practice, including hemodialysis, peritoneal dialysis, and kidney transplantation [7]. Although kidney transplantation is the optimal choice of ESRD treatment, challenges such as immunosuppression and organ donor shortage remain an issue [8,9]. Therefore, ESRD necessitates management using dialysis to postpone imminent death $[9,10]$. Among advanced CKD or ESRD treatment modalities, hemodialysis was found to be the primary approach of dialysis treatment for kidney failure, and around $90 \%$ of all patients undergoing dialysis received hemodialysis [11,12]. According to a recent, nationwide cohort study [13], hemodialysis patients had a lower adjusted risk of death compared with those on peritoneal dialysis. However, the hemodialysis patients still have higher mortality 
as well as multimorbidity and hospitalizations than the general population [14]. According to previous studies, several factors such as age, presence of diabetes mellitus, history of cardiovascular events, and elevated high-sensitivity C-reactive protein were reported as risk factors for mortality in hemodialysis patients [14-16]. However, the risk factors for mortality in ESRD patients undergoing hemodialysis are not fully understood.

Frailty is characterized by reduced cognitive and physiologic reserves which lead to greater vulnerability [17]. Frailty is prevalent in patients with all stages of CKD and two-thirds of patients with ESRD [18,19]. ESRD patients with frailty are vulnerable to adverse outcomes including an increased risk of disability, hospitalization, and mortality [19]. Two previous studies have also demonstrated the relationship between frailty in hemodialysis and adverse outcome, such as death [20,21]. Moreover, despite improved care and innovative technological advancements in hemodialysis, the mortality of patients with ESRD is 10-30 times greater than that of the general population [22]. Although frailty before ESRD has been evaluated as a risk factor for short- and long-term mortality in adults with ESRD, the impact of preexisting or coexisting frailty on mortality after ESRD among adult patients of all ages is unclear. Hence, it is meaningful to synthesize and analyze whether frailty has an impact on mortality among adults with ESRD undergoing hemodialysis. Strategies to reduce the risk of mortality associated with hemodialysis among ESRD patients should continue to be a high clinical priority. In addition, identifying prevalence and risk factors of frailty in ESRD patients undergoing hemodialysis may be meaningful for creating strategies designed to reduce the burden on patients and their family members.

A previous systematic review [23] investigated the assessment for frailty in pre-dialysis patients and reported that it is associated with CKD. This review highlighted that it is difficult to examine the causal relationship between the factors identified and frailty, as well as the association between frailty and mortality [23]. To our knowledge, careful analysis of the impact of frailty on mortality of ESRD patients undergoing hemodialysis has not yet been performed. Therefore, this study aimed to investigate whether frailty is associated with mortality in hemodialysis patients with ESRD based on a review of cohort studies. In addition, we aimed to explore the prevalence and associated factors of frailty in ESRD patients on hemodialysis.

\section{Materials and Methods}

\subsection{Search Strategies}

We conducted a systematic review, prospectively registered on PROSPERO (ID: CRD42021228373). This systematic review was performed based on the Preferred Reporting Items for Systematic Reviews and Meta-Analysis (PRISMA) guidelines [24]. We organized the research question according to the "PICO" format [25], which was: What is the prevalence and associated factors of frailty (Interest) and the association of frailty and mortality (Outcome) in patients with ESRD undergoing hemodialysis (Patient), compared with patients without hemodialysis-dependent ESRD (Comparator)? Our systematic review was conducted by reviewing the literature in electronic databases such as PubMed, Embase, CINAHL, Web of Science, and Cochrane Library for cohort studies published until 30 November 2020.

Medical Subject Heading (MeSH) and non-MeSH keywords were used in the search strategy based on our research question: "frailty or frail", "dialysis or hemodialysis", "chronic kidney disease or CKD or end-stage renal disease or ESRD", and "mortality or death or outcome". Additional searches were conducted on Google Scholar and in grey literature sources such as conferences and government websites. The reference lists of full-text articles were also examined.

\subsection{Study Selection}

From the retrieved results, two researchers (Y.J.S. and H.J.L.) screened all abstracts to verify potentially relevant articles for this review. Then, the full text of studies were independently assessed to verify articles that were qualified to be included. Any dis- 
agreement encountered was settled by discussion. In this review, the inclusion criteria were as follows: (1) studies reporting the association of frailty and mortality including the prevalence and associated factors of frailty among patients undergoing hemodialysis ( $\geq 18$ years of age), (2) cohort studies (prospective or retrospective), (3) reporting of the hazard ratio (HR) or odds ratio (OR) and standardized mean difference (SMD) with $95 \%$ confidence interval (CI) or eligible data to calculate these figures, and (4) full text published in English in peer-reviewed journals. The exclusion criteria were: (1) case-control studies or cross-sectional studies, clinical trials, reviews, editorials, letters, and abstracts, and (2) patients undergoing peritoneal dialysis or kidney transplantation.

\subsection{Data Extraction and Synthesis}

Data were extracted by two researchers (Y.J.S. and H.J.L.) using a prespecified form. These data included the first author's last name, publication year, country, study design, follow-up period, frailty scale, definition of frailty, participants' characteristics (e.g., sample size for frail and non-frail patients, mean age, and sex), prevalence of frailty, outcome, and adjustments for covariates.

\subsection{Data Analysis}

Among the risk factors associated with frailty in patients with ESRD undergoing hemodialysis, the binomial variables are presented as OR with $95 \% \mathrm{CI}$, and the continuous variable is presented as SMD with $95 \%$ CI. The all-cause mortality in patients with ESRD undergoing hemodialysis is presented as HR with $95 \%$ CI. Statistical heterogeneity in the results was calculated by $Q$ statistics ( $p<0.05$ considered statistically significant) and quantified using $\mathrm{I}^{2}$ statistics. A value of $\mathrm{I}^{2}$ indicating $25 \%, 50 \%$, or $>75 \%$ heterogeneity was considered as low, moderate, or high heterogeneity, respectively [26]. If moderate or high heterogeneity was confirmed, we utilized a random effects model to pool outcomes. Conversely, if low heterogeneity was confirmed, we utilized a fixed effects model [27]. Publication bias was assessed using Egger's linear regression tests [28]. Meta-analysis was conducted using Comprehensive Meta-Analysis software (version 3.0; Biostat, Englewood, NJ, USA).

\subsection{Quality Assessment of the Studies Included}

The Newcastle-Ottawa Scale (NOS) was used for assessing the quality of cohort studies [29]. This scale has four items that examine selection categories, one that examines comparability, and three items that examine outcome categories. Each item is awarded a maximum of one star within selection and outcome categories. A maximum of two stars can be given for comparability. Studies scoring $\geq 7$ were judged to be of good quality, 5-6 as fair quality, and $<5$ as poor quality. Two researchers (Y.J.S. and H.J.L.) independently judged the studies for risk of bias. Any discrepancies encountered were settled by discussion.

\section{Results}

\subsection{Study Selection}

The PRISMA selection process is shown in Figure 1. A total of 752 studies were retrieved through database searches. After removal of duplicates, we reviewed the title and abstract of 645 relevant studies. Of these articles, 601 were excluded, leaving 44 articles for full-text review. A total 37 articles were excluded for the reasons described in Figure 1, which finally left seven articles for the meta-analysis. 


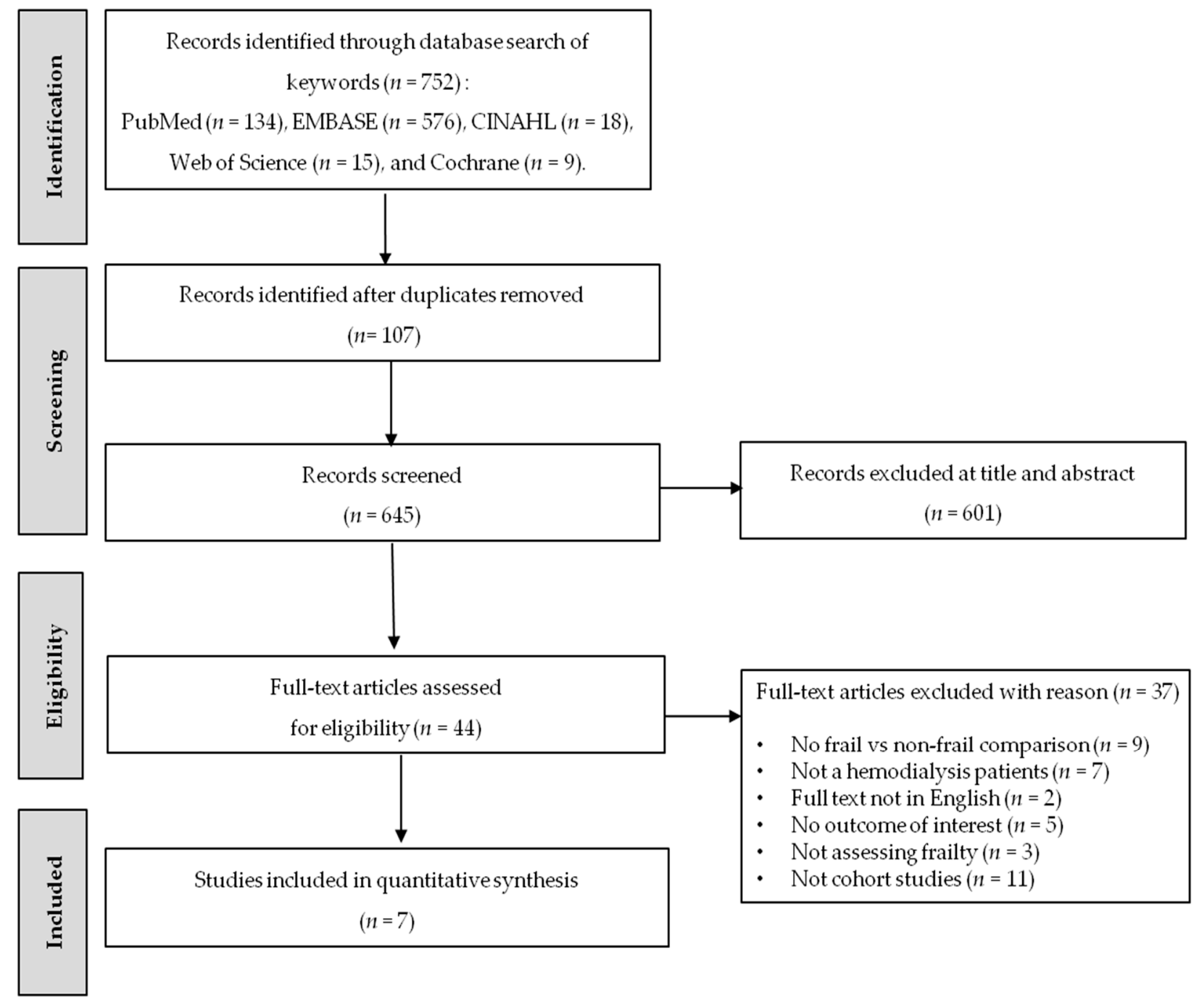

Figure 1. Preferred Reporting Items for Systematic Reviews and Meta-Analysis (PRISMA) flow diagram for study selection.

\subsection{Characteristics of the Included Studies}

The characteristics of the included studies are described in Table 1. According to study design, the types of cohort studies in this review included six prospective cohort studies [20,30-34] and one retrospective cohort study [35]. The follow-up periods ranged from 12 to 36 months. In terms of assessment tools for measuring frailty, six studies used the Fried phenotype, determining frailty if three or more of the five components were present [30-35]. One study using the Edmonton Frail Scale identified frailty when a score of more than 8 out of 17 was obtained [20]. The cohort size of the studies ranged from 117 to 762 , with a total of 2604 patients, and the number of frailty cases ranged from 63 to 240 , with a total of 1036. The mean ages of the study populations ranged from 44.9 to 78.1 years. All the studies achieved a NOS methodological quality score ranged 7 to 8 , which means good quality. 
Table 1. Characteristics of studies included $(n=7)$.

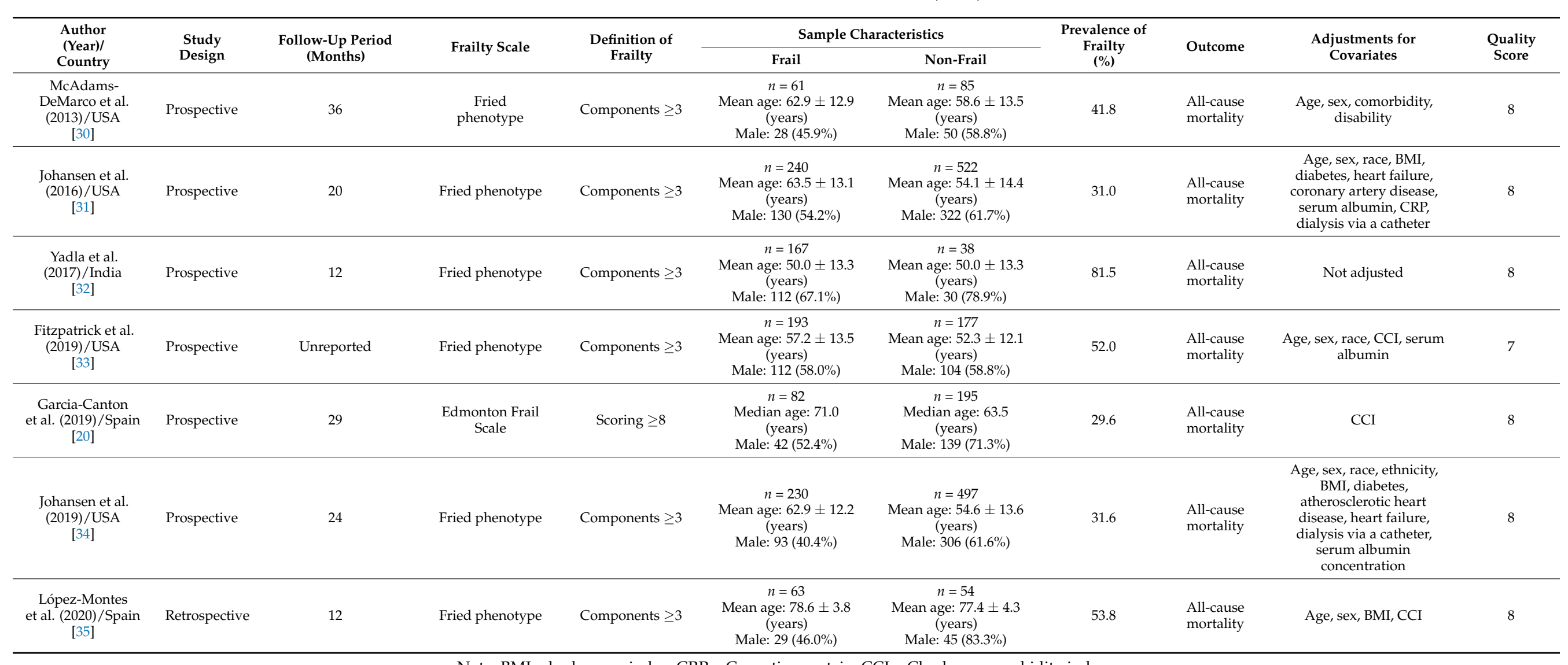

Note. $\mathrm{BMI}=$ body mass index; $\mathrm{CRP}=\mathrm{C}$-reactive protein; $\mathrm{CCI}=$ Charlson comorbidity index . 


\subsection{Prevalence of Frailty in Patients Undergoing Hemodialysis}

The prevalence of frailty ranged from $29.6 \%$ to $81.5 \%$ among all studies. The overall prevalence of frailty in patients with ESRD undergoing hemodialysis was $46.0 \%$ ( $95 \%$ CI: $34.2-58.3 \%$ ). A random effects model was utilized for analysis because there was heterogeneity between them $\left(\mathrm{I}^{2}=96 \%, p<0.001\right)$ (Figure 2).

\begin{tabular}{|c|c|c|c|c|c|c|c|c|c|}
\hline Study & ES & $\begin{array}{c}\text { Lower } \\
\text { Limit }\end{array}$ & $\begin{array}{l}\text { Upper } \\
\text { Limit }\end{array}$ & Z-Value & $p$-Value & \multicolumn{4}{|c|}{ ES and $95 \% \mathrm{CI}$} \\
\hline McAdams-DeMarco et (2013)[30] & 0.42 & 0.34 & 0.50 & -1.98 & 0.048 & & & & \\
\hline Johansen et al.(2016) [31] & 0.32 & 0.28 & 0.35 & -9.96 & $<0.001$ & & & & \\
\hline Yadla et al. (2017) [32] & 0.82 & 0.76 & 0.86 & 8.24 & $<0.001$ & & & & \\
\hline Fitzpatrick et al.(2019) [33] & 0.52 & 0.47 & 0.57 & 0.83 & 0.406 & & & & \\
\hline Garcia-Canton et al.(2019) [20] & 0.30 & 0.25 & 0.35 & -6.58 & $<0.001$ & & & & \\
\hline Johansen et al. (2019) [34] & 0.32 & 0.28 & 0.35 & -9.66 & $<0.001$ & & & & \\
\hline López-Montes et al.(2020) [35] & 0.54 & 0.45 & 0.63 & 0.83 & 0.406 & & & & \\
\hline Total & 0.46 & 0.34 & 0.58 & -0.63 & 0.527 & & & & \\
\hline \multicolumn{6}{|c|}{$\mathrm{I}^{2}=96 \%, p<0.001$, Egger's test $p=0.101$} & -1.00 & -0.50 & 0.00 & 1.00 \\
\hline
\end{tabular}

Note. $\mathrm{ES}=$ effect size; $\mathrm{CI}=$ confidence interval.

Figure 2. Forest plot of prevalence frailty in patients undergoing hemodialysis.

\subsection{Risk Factors for Frailty in Hemodialysis Patients}

We identified 11 risk factors for frailty among patients with ESRD undergoing hemodialysis (Table 2). However, only three factors including advanced age, female sex, and diabetes mellitus were significantly associated with frailty.

Table 2. Risk factors for frailty in hemodialysis patients.

\begin{tabular}{|c|c|c|c|c|c|c|c|}
\hline Risk Factors & $\begin{array}{l}\text { No. of } \\
\text { Studies }\end{array}$ & $\begin{array}{c}\text { No. of } \\
\text { Participants }\end{array}$ & OR/SMD & $95 \% \mathrm{CI}$ & $I^{2}(\%)$ & $p$-Value & Egger's Test $p$ \\
\hline \multicolumn{8}{|c|}{ Demographic characteristics } \\
\hline Age (years) & 6 & 1787 & $0.43 *$ & $0.24-0.61$ & 72 & 0.003 & 0.018 \\
\hline Sex (female) & 7 & 2604 & 1.89 & $1.33-2.67$ & 71 & 0.002 & 0.395 \\
\hline Smoking, yes & 3 & 721 & 1.39 & $0.58-3.32$ & 80 & 0.005 & 0.186 \\
\hline \multicolumn{8}{|c|}{ Comorbidities } \\
\hline Diabetes mellitus, yes & 7 & 2604 & 2.42 & $1.68-3.49$ & 73 & 0.001 & 0.108 \\
\hline Hypertension, yes & 3 & 721 & 2.16 & $0.46-10.04$ & 82 & 0.003 & 0.472 \\
\hline CAD, yes & 3 & 1249 & 0.96 & $0.63-1.46$ & 57 & 0.098 & 0.668 \\
\hline PVD, yes & 5 & 1600 & 1.87 & $0.81-4.29$ & 68 & $<0.001$ & 0.240 \\
\hline HF, yes & 4 & 1483 & 1.35 & $0.92-2.00$ & 57 & 0.070 & 0.588 \\
\hline CVA or TIA, yes & 4 & 1454 & 1.96 & $0.93-4.17$ & 73 & 0.011 & 0.161 \\
\hline COPD, yes & 3 & 633 & 1.43 & $0.98-2.09$ & 0 & 0.835 & 0.532 \\
\hline Cancer, yes & 2 & 516 & 1.35 & $0.48-3.84$ & 68 & 0.077 & NA \\
\hline
\end{tabular}

Note. ${ }^{*} \mathrm{SMD}=$ standardized mean difference; $\mathrm{OR}=$ odds ratio; $\mathrm{CI}=$ confidence interval; $\mathrm{CAD}=$ coronary artery disease; $\mathrm{PVD}=$ peripheral vascular disease; $\mathrm{HF}=$ heart failure; $\mathrm{CVA}=$ cerebral vascular disease; $\mathrm{TIA}=$ transient ischemic attack; $\mathrm{COPD}=$ chronic obstructive pulmonary disease.

\subsubsection{Age}

Six studies [29-34] assessed the association between age and frailty in ESRD patients undergoing hemodialysis. We used a random effects model for these studies because there was heterogeneity between them $\left(\mathrm{I}^{2}=72 \%, p=0.003\right)$. The results showed that advanced age was a risk factor for frailty in patients undergoing hemodialysis (SMD: 0.43 years; 95\% CI: 0.24-0.61) (Table 2). 


\subsubsection{Female Sex}

All studies included in this review identified an association between sex of the patient and frailty in ESRD patients undergoing hemodialysis. A random effects model was utilized to analyze the studies because they were heterogenous $\left(\mathrm{I}^{2}=71 \%, p=0.002\right)$. The results indicated that being female was a risk factor for frailty in ESRD patients undergoing hemodialysis (OR: 1.89; 95\% CI: 1.33-2.67) (Table 2).

\subsubsection{Diabetes Mellitus}

All studies included in this review investigated the association between diabetes mellitus and frailty in ESRD patients undergoing hemodialysis. A random effects model was utilized to analyze these seven studies because they were heterogenous $\left(\mathrm{I}^{2}=73 \%\right.$, $p=0.001$ ). The results showed that diabetes mellitus was a risk factor for frailty in ESRD patients undergoing hemodialysis (OR: 2.42; 95\% CI: 1.68-3.49) (Table 2).

\subsection{All-Cause Mortality for Hemodialysis Patients with Frailty}

All studies included in this review utilized a fixed effects model because there was low heterogeneity $\left(\mathrm{I}^{2}=8 \%, p=0.368\right)$. Compared to hemodialysis patients with non-frailty, hemodialysis patients with frailty had a greater all-cause mortality risk (HR: 2.02, 95\% CI: 1.65-2.48) (Figure 3).

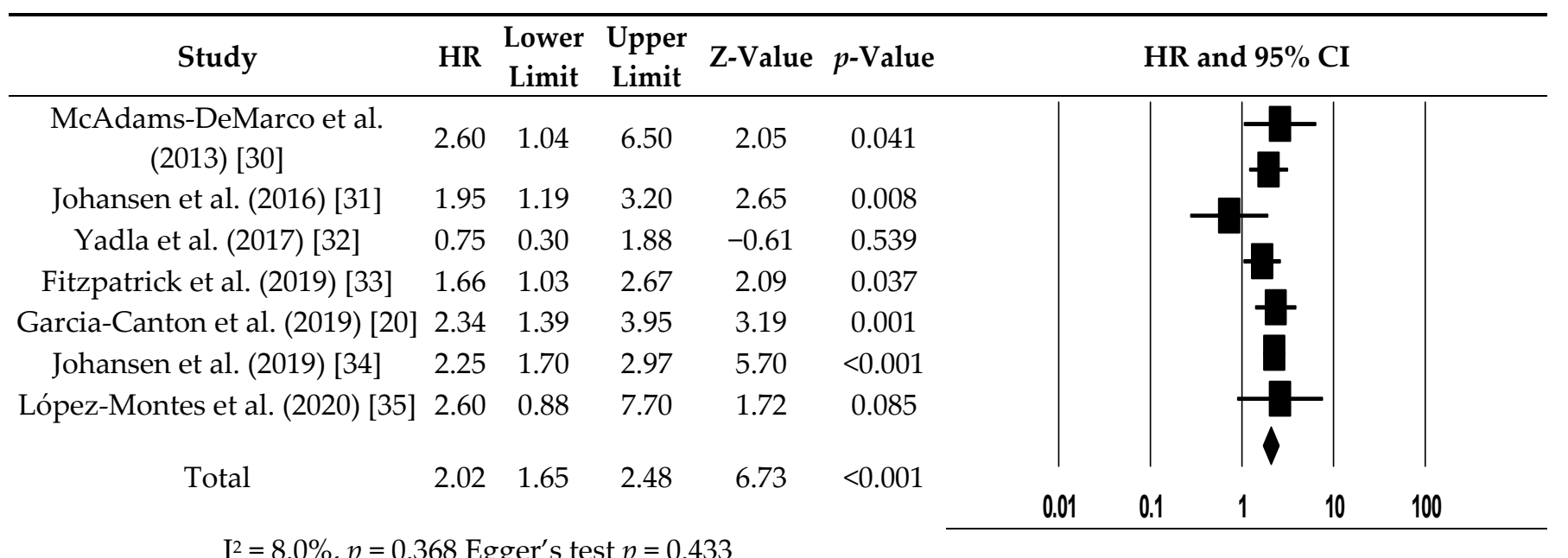

$\mathrm{I}^{2}=8.0 \%, p=0.368$ Egger's test $p=0.433$

Note. $\mathrm{HR}=$ hazard ratio; $\mathrm{CI}=$ confidence interval.

Figure 3. Forest plot of all-cause mortality for hemodialysis patients with frailty.

\section{Discussion}

Our findings demonstrate that frailty increases the risk of all-cause mortality in ESRD patients undergoing hemodialysis, which is similar to previous reviews [18,36]. Frailty is a multidimensional syndrome that leads to decline in activity and inadequate response to health stressors due to sarcopenia, vulnerability, and impaired endurance [18]. Particularly, patients undergoing hemodialysis inevitably experience amino acid and protein losses through hemodialysis [37,38]. In addition, ESRD itself is likely to lead to frailty, due to insulin resistance, chronic inflammation, and vascular calcification resulting in loss of musculoskeletal mass [39-41]. For these reasons, ESRD patients on hemodialysis have an increased risk of frailty due to reduced protein reserves and body energy and decreased strength, which can lead to difficulties in self-care ability as a key component of long-term survival in renal care $[7,19]$. However, many of the mechanisms by which frailty leads to an increase in mortality are still not well defined. Further research is required to determine the mechanisms by which frailty increases the risk of mortality.

Importantly, this review revealed that the prevalence of frailty in ESRD patients on hemodialysis was approximately $43 \%$. Our finding was similar to a recent meta- 
analysis [42] that showed a $34 \%$ prevalence of frailty in patients undergoing hemodialysis. A systematic review by Chowdhury et al. also confirmed that the prevalence of frailty in dialysis patients was higher compared to non-dialysis patients [43]. Therefore, early assessment of frailty in patients undergoing hemodialysis is a vital factor for preventing the risk of mortality as well as disability and unplanned rehospitalization. Moreover, we found that there was a difference in the prevalence according to the type of assessment tool used to measure frailty. In our review, the most common screening tool for frailty was the Fried phenotype, with prevalence of frailty ranging from 31.0-81.5\% [30-35]. Only one study used the Edmonton Frail Scale to measure frailty and found that the prevalence of frailty was $26 \%$, lower than that found using the Fried phenotype [20]. The Fried phenotype is the most widely used validated method for frailty assessment [43]. However, this tool focuses on physiological frailty and has limitations for assessing the severity of frailty in a population with a high prevalence of frailty [44,45]. Whereas the Edmonton Frail Scale is a multiple domain tool that assesses various dimensions of frailty, including cognitive state, degree of dependence, social support, a physiological dimension, and a psychological dimension [46]. However, the Edmonton Frail Scale has only been used in a few studies [47,48]. Assessments of frailty for hemodialysis patients should include the risk factors related to its incidence and progression and should also be assessed with an expanded concept that includes not only physical but also psychological and cognitive frailty $[17,19]$. Therefore, it is necessary to develop a standardized assessment tool for screening frailty in patients undergoing hemodialysis.

Our findings show that advanced age, female sex, and presence of diabetes mellitus were risk factors for the progression and development of frailty. Moreover, this review found that older patients undergoing hemodialysis were more at risk of frailty. This result was consistent with recent studies showing a close correlation between frailty and aging $[49,50]$. Aging causes conditions such as chronic diseases, depressive symptoms, and declined cognitive and functional capacity, and aging increases the likelihood of developing frailty [51]. Particularly, ESRD may accelerate the aging process in patients due to uremic toxins, inflammations, protein energy waste, and oxidative stress [52]. Therefore, health professionals should pay close attention to older ESRD patients undergoing hemodialysis and take actions to prevent the development and progression of frailty. Meanwhile, in the present study, the highest prevalence of frailty was confirmed in the population with a mean age of 44 years [32], indicating the need for further investigation to determine causality between younger age and frailty in ESRD patients undergoing hemodialysis. Females also had higher rates of frailty in ESRD patients on hemodialysis. This result is in line with a previous meta-analysis examining frailty by sex; female patients were found to have a higher degree of frailty than male patients, across all age groups [53]. In female older adults with frailty, there are multiple anabolic hormonal deficiencies, of which the declining levels of testosterone is correlated with frailty $[54,55]$. Hence, health professionals are required to explore gender or sex differences in hemodialysis patients' frailty status, which can be helpful for developing an individualized or patient-centered approach for improving health outcomes, including quality of life. Diabetes mellitus, which can increase the risk of frailty, has long been known as the leading cause of ESRD [56]. Our findings support the results from previous studies showing that diabetes mellitus was associated with frailty in patients undergoing hemodialysis. Kakio et al. demonstrated that diabetic kidney disease patients are significantly more at risk of frailty than nondiabetic CKD patients [57]. Diabetic patients are more at risk because of the combination of neuropathy with physiological dysfunction, impaired cognitive function resulting from cerebrovascular disease or brain degeneration, inflammation mechanisms, and the loss of self-care capacity $[58,59]$. Therefore, hemodialysis patients with diabetes mellitus should be classified as a risk group for developing frailty, requiring more careful and specific assessment and different treatment strategies to relieve or prevent their physiological and cognitive dysfunction. 
Although ESRD is a major global health problem, six of the seven studies included in this review were performed in Western countries for example, the United States of America and Spain. According to a study spanning 142 countries, the population of ESRD patients is increasing worldwide, with the highest rate observed in the Western Pacific Region [60]. Especially, the number of ESRD patients who need dialysis treatment in Asia is growing at a higher rate than other parts of the world [61]. Therefore, future studies for the prevention of frailty and mortality in ESRD patients undergoing hemodialysis should be conducted using large-scale international comparisons. We pooled adjusted risk estimates in this meta-analysis. In each individual study, the age and sex were adjusted in common, but other risk factors that could affect all-cause mortality, such as comorbidities, were not adjusted in common in all studies. Future research should adjust the risk factors that may affect mortality in ESRD patients in order to more clearly establish the association of frailty with all-cause mortality.

Our study has several limitations. First, the meta-analysis of the prevalence of frailty showed high heterogeneity, but the cause of heterogeneity was not found due to the small number of studies in the final analysis. Second, we could not determine the psychological or behavioral risk factors in this review. Therefore, further studies are needed to consider the impact of psychological or behavioral factors such as cognitive function, depression, and nutritional patterns on frailty and its clinical outcomes in patients undergoing hemodialysis. Third, future studies should develop a validated screening tool for assessing the frailty of ESRD patients, which could help to predict accurate rates of frailty prevalence for this population. Finally, this review did not include studies published in languages other than English.

\section{Conclusions}

This review emphasized that frailty is a significant predictor of all-cause mortality in patients with ESRD undergoing hemodialysis. Healthcare professionals should develop a standardized tool for assessing renal-specific frailty and design individualized support programs to improve health outcomes for patients considering factors such as advanced age, sex, and comorbidities. Our results need to be confirmed through large multicenter cohort studies on the impact of frailty on poor health outcomes.

Author Contributions: Conceptualization, methodology, data analysis, draft preparation, and final manuscript editing: Y.-J.S. and H.-J.L. All authors have read and agreed to the published version of the manuscript.

Funding: This research was funded by the Tongmyong University Research Grants 2020, grant number 2020A013.

Institutional Review Board Statement: The study did not require ethical approval.

Informed Consent Statement: The study did not require an informed consent statement.

Data Availability Statement: The datasets used and/or analyzed during the current study are available from the corresponding author on reasonable request.

Conflicts of Interest: The authors declare no conflict of interest.

\section{References}

1. Gaitonde, D.Y.; Cook, D.L.; Rivera, I.M. Chronic kidney disease: Detection and evaluation. Am. Fam. Physician 2017, 96, 776-783. [PubMed]

2. Ene-Iordache, B.; Perico, N.; Bikbov, B.; Carminati, S.; Remuzzi, A.; Perna, A.; Islam, N.; Bravo, R.F.; Aleckovic-Halilovic, M.; Zou, H.; et al. Chronic kidney disease and cardiovascular risk in six regions of the world (ISN-KDDC): A cross-sectional study. Lancet Glob. Health 2016, 4, 1-13. [CrossRef]

3. Mills, K.T.; Xu, Y.; Zhang, W.; Bundy, J.D.; Chen, C.S.; Kelly, T.N.; Chen, J.; He, J. A systematic analysis of worldwide populationbased data on the global burden of chronic kidney disease in 2010. Kidney Int. 2015, 88, 950-957. [CrossRef]

4. Fung, E.; Kurella Tamura, M. Epidemiology and public health concerns of CKD in older adults. Adv. Chronic Kidney Dis. 2016, 23, 8-11. [CrossRef] 
5. Sharief, S.; Hsu, C.Y. The transition from the pre-ESRD to ESRD phase of CKD: Much remains to be learned. Am. J. Kidney Dis. 2017, 69, 8-10. [CrossRef] [PubMed]

6. Himmelfarb, J.; Vanholder, R.; Mehrotra, R.; Tonelli, M. The current and future landscape of dialysis. Nat. Rev. Nephrol. 2020, 16, 573-585. [CrossRef]

7. Rodger, R.S. Approach to the management of end stage renal disease. Clin. Med. 2012, 12, 472-475. [CrossRef]

8. Zhang, L.; Guo, Y.; Ming, H. Effects of hemodialysis, peritoneal dialysis, and renal transplantation on the quality of life of patients with end-stage renal disease. Rev. Assoc. Med. Bras. 2020, 66, 1229-1234. [CrossRef]

9. Garcia, G.G.; Harden, P.; Chapman, J. The global role of kidney transplantation. Indian J. Nephrol. 2012, 22, 77-82. [CrossRef]

10. Elshahat, S.; Cockwell, P.; Maxwell, A.P.; Griffin, M.; O’Brien, T.; O'Neill, C. The impact of chronic kidney disease on developed countries from a health economics perspective: A systematic scoping review. PLoS ONE 2020, 15, e0230512. [CrossRef]

11. Johnson, D.S.; Meyer, K.B. Delaying and averting dialysis treatment: Patient protection or moral hazard? Am. J. Kidney Dis. 2018, 72, 251-254. [CrossRef]

12. De Rosa, S.; Samoni, S.; Villa, G.; Ronco, C. Management of chronic kidney disease patients in the intensive care unit: Mixing acute and chronic illness. Blood Purif. 2017, 43, 151-162. [CrossRef]

13. Thiery, A.; Séverac, F.; Hannedouche, T.; Couchoud, C.; Do, V.H.; Tiple, A.; Béchade, C.; Sauleau, E.A.; Krummel, T.; REIN Registry. Survival advantage of planned haemodialysis over peritoneal dialysis: A cohort study. Nephrol. Dial. Transplant. 2018, 33, 1411-1419. [CrossRef] [PubMed]

14. Song, Y.H.; Cai, G.Y.; Xiao, Y.F.; Chen, X.M. Risk factors for mortality in elderly haemodialysis patients: A systematic review and meta-analysis. BMC Nephrol. 2020, 21, 1-10. [CrossRef]

15. Morfin, J.A.; Fluck, R.J.; Weinhandl, E.D.; Kansal, S.; McCullough, P.A.; Komenda, P. Intensive hemodialysis and treatment complications and tolerability. Am. J. Kidney Dis. 2016, 68, S43-S50. [CrossRef] [PubMed]

16. Taheri, S.; Baradaran, A.; Aliakbarian, M.; Mortazavi, M. Level of inflammatory factors in chronic hemodialysis patients with and without cardiovascular disease. J. Res. Med. Sci. 2017, 22, 1-5.

17. Chen, X.; Mao, G.; Leng, S.X. Frailty syndrome: An overview. Clin. Interv. Aging 2014, 9, 433-441.

18. Zhang, Q.; Ma, Y.; Lin, F.; Zhao, J.; Xiong, J. Frailty and mortality among patients with chronic kidney disease and end-stage renal disease: A systematic review and meta-analysis. Int. Urol. Nephrol. 2020, 52, 363-370. [CrossRef]

19. Lee, S.W.; Lee, A.; Yu, M.Y.; Kim, S.W.; Kim, K.I.; Na, K.Y.; Chae, D.W.; Kim, C.H.; Chin, H.J. Is frailty a modifiable risk factor of future adverse outcomes in elderly patients with incident end-stage renal disease? J. Korean Med. Sci. 2017, 32, 1800-1806. [CrossRef]

20. Garcia-Canton, C.; Rodenas, A.; Lopez-Aperador, C.; Rivero, Y.; Anton, G.; Monzon, T.; Diaz, N.; Vega, N.; Loro, J.F.; Santana, A.; et al. Frailty in hemodialysis and prediction of poor short-term outcome: Mortality, hospitalization and visits to hospital emergency services. Ren. Fail. 2019, 41, 567-575. [CrossRef]

21. Msaad, R.; Essadik, R.; Mohtadi, K.; Meftah, H.; Lebrazi, H.; Taki, H.; Kettani, A.; Madkouri, G.; Ramdani, B.; Saïle, R. Predictors of mortality in hemodialysis patients. Pan. Afr. Med. J. 2019, 33, 1-14. [CrossRef] [PubMed]

22. Sy, J.; Johansen, K.L. The impact of frailty on outcomes in dialysis. Curr. Opin. Nephrol. Hypertens. 2017, 26, 537-542. [CrossRef] [PubMed]

23. Walker, S.R.; Gill, K.; Macdonald, K.; Komenda, P.; Rigatto, C.; Sood, M.M.; Bohm, C.J.; Storsley, L.J.; Tangri, N. Association of frailty and physical function in patients with non-dialysis CKD: A systematic review. BMC Nephrol. 2013, 14, 1-9. [CrossRef] [PubMed]

24. Moher, D.; Shamseer, L.; Clarke, M.; Ghersi, D.; Liberati, A.; Petticrew, M.; Shekelle, P.; Stewart, L.A.; PRISMA Group. Preferred reporting items for systematic review and meta-analysis protocols (PRISMA-P) 2015 statement. Syst. Rev. 2015, 4, 1-9. [CrossRef]

25. Haynes, R.B.; Sacket, D.L.; Guyatt, G.H.; Tugwell, P. Clinical Epidemiology: How Clinical Practice Research, 3rd ed.; Lippincott Williams \& Wilkins: Philadelphia, PA, USA, 2006; pp. 273-322.

26. Higgins, J.P.T.; Thompson, S.G. Quantifying heterogeneity in a meta-analysis. Stat. Med. 2002, 21, 1539-1558. [CrossRef]

27. Higgins, J.P.; Thompson, S.G.; Deeks, J.J.; Altman, D.G. Measuring inconsistency in meta-analyses. BMJ 2003, 327, 557-560. [CrossRef]

28. Egger, M.; Davey Smith, G.; Schneider, M.; Minder, C. Bias in meta-analysis detected by a simple, graphical test. BMJ 1997, 315, 629-634. [CrossRef]

29. Wells, G.A.; Shea, B.; O'Connell, D.; Peterson, J.; Welch, V.; Losos, M.; Tugwell, P. The Newcastle-Ottawa Scale (NOS) for Assessing the Quality of Nonrandomised Studies in Meta-Analyses. Available online: http://www.ohri.ca/programs/clinical_ epidemiology / oxford.asp (accessed on 20 June 2019).

30. McAdams-DeMarco, M.A.; Law, A.; Salter, M.L.; Boyarsky, B.; Gimenez, L.; Jaar, B.G.; Walston, J.D.; Segev, D.L. Frailty as a novel predictor of mortality and hospitalization in individuals of all ages undergoing hemodialysis. J. Am. Geriatr. Soc. 2013, 61, 896-901. [CrossRef]

31. Johansen, K.L.; Dalrymple, L.S.; Glidden, D.; Delgado, C.; Kaysen, G.A.; Grimes, B.; Chertow, G.M. Association of performancebased and self-reported function-based definitions of frailty with mortality among patients receiving hemodialysis. Clin. J. Am. Soc. Nephrol. 2016, 11, 626-632. [CrossRef]

32. Yadla, M.; John, J.P.; Mummadi, M. A study of clinical assessment of frailty in patients on maintenance hemodialysis supported by cashless government scheme. Saudi J. Kidney Dis. Transpl. 2017, 28, 15-22. [CrossRef] 
33. Fitzpatrick, J.; Sozio, S.M.; Jaar, B.G.; Estrella, M.M.; Segev, D.L.; Parekh, R.S.; McAdams-DeMarco, M.A. Frailty, body composition and the risk of mortality in incident hemodialysis patients: The predictors of arrhythmic and cardiovascular risk in end stage renal disease study. Nephrol. Dial. Transplant. 2019, 34, 346-354. [CrossRef]

34. Johansen, K.L.; Delgado, C.; Kaysen, G.A.; Chertow, G.M.; Chiang, J.; Dalrymple, L.S.; Segal, M.R.; Grimes, B.A. Frailty among patients receiving hemodialysis: Evolution of components and associations with mortality. J. Gerontol. A Biol. Sci. Med. Sci. 2019, 74, 380-386. [CrossRef]

35. López-Montes, A.; Martínez-Villaescusa, M.; Pérez-Rodríguez, A.; Andrés-Monpeán, E.; Martínez-Díaz, M.; Masiá, J.; GiménezBachs, J.M.; Abizanda, P. Frailty, physical function and affective status in elderly patients on hemodialysis. Arch. Gerontol. Geriatr. 2020, 87, 1-7. [CrossRef]

36. Mei, F.; Gao, Q.; Chen, F.; Zhao, L.; Shang, Y.; Hu, K.; Zhang, W.; Zhao, B.; Ma, B. Frailty as a predictor of negative health outcomes in chronic kidney disease: A systematic review and meta-analysis. J. Am. Med. Dir. Assoc. 2021, 22, 535-543.e7. [CrossRef]

37. Moorthi, R.N.; Avin, K.G. Clinical relevance of sarcopenia in chronic kidney disease. Curr. Opin. Nephrol. Hypertens. 2017, 26, 219-228. [CrossRef]

38. Carrero, J.J.; Stenvinkel, P.; Cuppari, L.; Ikizler, T.A.; Kalantar-Zadeh, K.; Kaysen, G.; Mitch, W.E.; Price, S.R.; Wanner, C.; Wang, A.Y.; et al. Etiology of the protein-energy wasting syndrome in chronic kidney disease: A consensus statement from the International Society of Renal Nutrition and Metabolism (ISRNM). J. Ren. Nutr. 2013, 23, 77-90. [CrossRef] [PubMed]

39. Ballew, S.H.; Chen, Y.; Daya, N.R.; Godino, J.G.; Windham, B.G.; McAdams-DeMarco, M.; Coresh, J.; Selvin, E.; Grams, M.E. Frailty, kidney function, and polypharmacy: The Atherosclerosis Risk in Communities (ARIC) Study. Am. J. Kidney Dis. 2017, 69, 228-236. [CrossRef] [PubMed]

40. Cobo, G.; Lindholm, B.; Stenvinkel, P. Chronic inflammation in end-stage renal disease and dialysis. Nephrol. Dial. Transplant. 2018, 33, 1-6. [CrossRef]

41. Kooman, J.P.; Dekker, M.J.; Usvyat, L.A.; Kotanko, P.; van der Sande, F.M.; Schalkwijk, C.G.; Shiels, P.G.; Stenvinkel, P. Inflammation and premature aging in advanced chronic kidney disease. Am. J. Physiol. Renal. Physiol. 2017, 313, 938-950. [CrossRef] [PubMed]

42. Zhao, Y.; Liu, Q.; Ji, J. The prevalence of frailty in patients on hemodialysis: A systematic review and meta-analysis. Int. Urol. Nephrol. 2020, 52, 115-120. [CrossRef] [PubMed]

43. Chowdhury, R.; Peel, N.M.; Krosch, M.; Hubbard, R.E. Frailty and chronic kidney disease: A systematic review. Arch. Gerontol. Geriatr. 2017, 68, 135-142. [CrossRef] [PubMed]

44. Clegg, A.; Young, J.; Iliffe, S.; Rikkert, M.O.; Rockwood, K. Frailty in elderly people. Lancet 2013, 381, 752-762. [CrossRef]

45. Rockwood, K.; Song, X.; MacKnight, C.; Bergman, H.; Hogan, D.B.; McDowell, I.; Mitnitski, A. A global clinical measure of fitness and frailty in elderly people. CMAJ 2005, 173, 489-495. [CrossRef]

46. Rolfson, D.B.; Majumdar, S.R.; Tsuyuki, R.T.; Tahir, A.; Rockwood, K. Validity and reliability of the Edmonton frail scale. Age Ageing 2006, 35, 526-529. [CrossRef]

47. Chao, C.T.; Hsu, Y.H.; Chang, P.Y.; He, Y.T.; Ueng, R.S.; Lai, C.F.; Chiang, C.K.; Huang, J.W.; Huang, S.J. Simple self-report FRAIL scale might be more closely associated with dialysis complications than other frailty screening instruments in rural chronic dialysis patients. Nephrology 2015, 20, 321-328. [CrossRef]

48. Orlandi, F.S.; Gesualdo, G.D. Assessment of the frailty level of elderly people with chronic kidney disease undergoing hemodialysis. Acta Paul. Enferm. 2014, 27, 29-34. [CrossRef]

49. Lee, S.Y.; Yang, D.H.; Hwang, E.; Kang, S.H.; Park, S.H.; Kim, T.W.; Lee, D.H.; Park, K.; Kim, J.C. The Prevalence, association, and clinical outcomes of frailty in maintenance dialysis patients. J. Ren. Nutr. 2017, 27, 106-112. [CrossRef]

50. Takeuchi, H.; Uchida, H.A.; Kakio, Y.; Okuyama, Y.; Okuyama, M.; Umebayashi, R.; Wada, K.; Sugiyama, H.; Sugimoto, K.; Rakugi, H.; et al. The prevalence of frailty and its associated factors in Japanese hemodialysis patients. Aging Dis. 2018, 9, 192-207. [CrossRef]

51. Nitta, K.; Hanafusa, N.; Tsuchiya, K. Frailty and mortality among dialysis patients. Ren. Replace Ther. 2017, 3, 1-6. [CrossRef]

52. Nitta, K.; Tsuchiya, K. Recent advances in the pathophysiology and management of protein-energy wasting in chronic kidney disease. Ren. Replace Ther. 2016, 2, 1-12. [CrossRef]

53. Gordon, E.H.; Peel, N.M.; Samanta, M.; Theou, O.; Howlett, S.E.; Hubbard, R.E. Sex differences in frailty: A systematic review and meta-analysis. Exp. Gerontol. 2017, 89, 30-40. [CrossRef] [PubMed]

54. Varadhan, R.; Chaves, P.H.; Lipsitz, L.A.; Stein, P.K.; Tian, J.; Windham, B.G.; Berger, R.D.; Fried, L.P. Frailty and impaired cardiac autonomic control: New insights from principal components aggregation of traditional heart rate variability indices. J. Gerontol. A Biol. Sci. Med. Sci. 2009, 64, 682-687. [CrossRef] [PubMed]

55. Hyde, Z.; Flicker, L.; Almeida, O.P.; Hankey, G.J.; McCaul, K.A.; Chubb, S.A.; Yeap, B.B. Low free testosterone predicts frailty in older men: The health in men study. J. Clin. Endocrinol. Metab. 2010, 95, 3165-3172. [CrossRef]

56. Walker, S.R.; Wagner, M.; Tangri, N. Chronic kidney disease, frailty, and unsuccessful aging: A review. J. Ren. Nutr. 2014, 24, 364-370. [CrossRef] [PubMed]

57. Kakio, Y.; Uchida, H.A.; Takeuchi, H.; Okuyama, Y.; Okuyama, M.; Umebayashi, R.; Wada, K.; Sugiyama, H.; Sugimoto, K.; Rakugi, H.; et al. Diabetic nephropathy is associated with frailty in patients with chronic hemodialysis. Geriatr. Gerontol. Int. 2018, 18, 1597-1602. [CrossRef] 
58. Angulo, J.; El Assar, M.; Rodríguez-Mañas, L. Frailty and sarcopenia as the basis for the phenotypic manifestation of chronic diseases in older adults. Mol. Asp. Med. 2016, 50,1-32. [CrossRef]

59. Yanase, T.; Yanagita, I.; Muta, K.; Nawata, H. Frailty in elderly diabetes patients. Endocr. J. 2018, 65, 1-11. [CrossRef]

60. Cheng, H.T.; Xu, X.; Lim, P.S.; Hung, K.Y. Worldwide epidemiology of diabetes-related end-stage renal disease, $2000-2015$. Diabetes Care 2021, 44, 89-97. [CrossRef]

61. Prasad, N.; Jha, V. Hemodialysis in Asia. Kidney Dis. 2015, 1, 165-177. [CrossRef] 